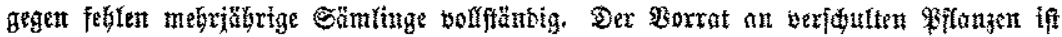
fnctpp.

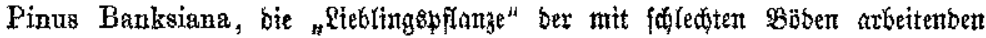

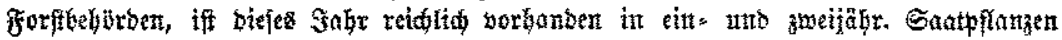
unt tabliäbrig verjwulten Eremplaten.

Larix en ropaea, Larix leptolepis, Pseudotsuga Douglasii, Picea alba,

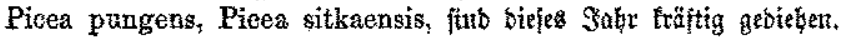

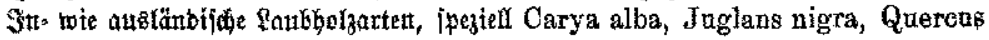
rubra find in grofen 3 eftüntroen vorhanten.

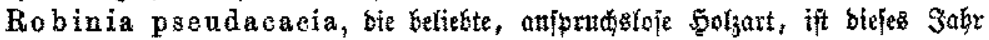

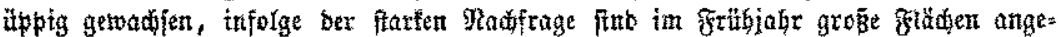
Iegt puorben; bas Sols war vor Begint ber erfen Fröfte fołon bollftänbig ausgereift.

Dr. Beter Earl ङ

\title{
forftbotanifhes ZMerfbuh.
}

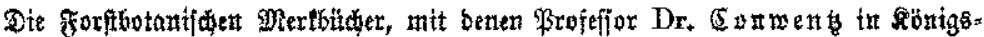

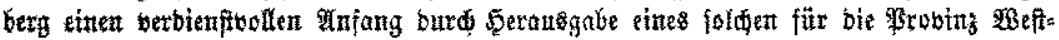

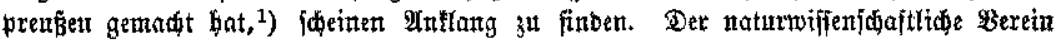

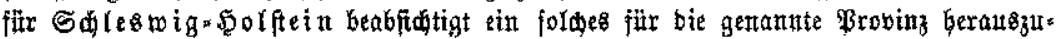

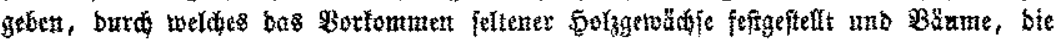

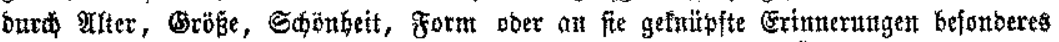

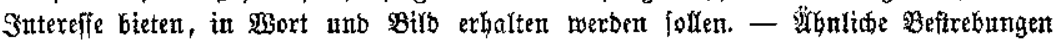

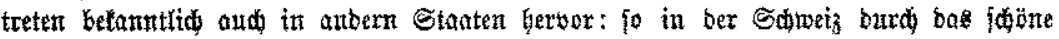

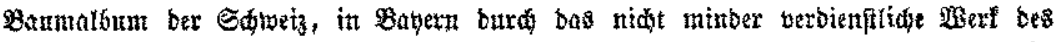

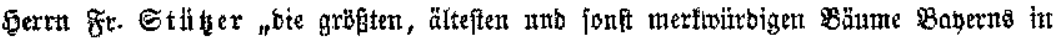

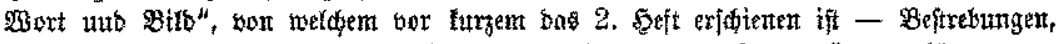

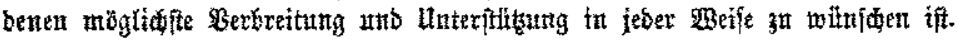

\section{Godifhuluathrihten.}

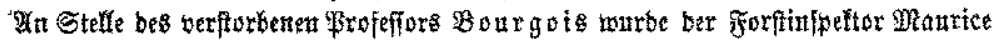

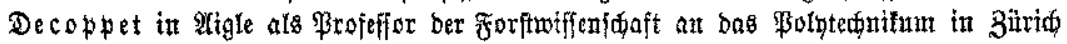
berufen.

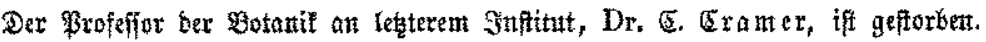

\section{Todesanzetge.}

An 27. Dezember 1901 verftarb rajo und unerwartet infolge eines Salagans

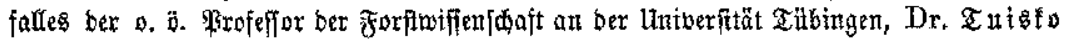

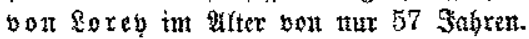

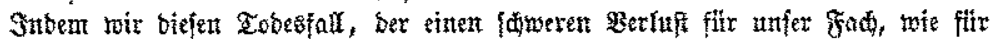
bie zahlretalen Freunbe bes jo jrifgzeitig Entjoflaferten Eesentet, in aufribtiger Feilnahnte zun Senntnio unferer Sefer bringen, behalten wir unz einen Sebensnbrip besjelben für

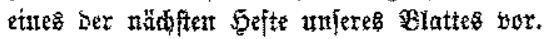

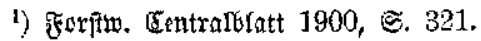

